\title{
How to start a successful robotic mitral surgery program: It's not just about the surgery!
}

\author{
Hanjay Wang, MD, and Jack H. Boyd, MD
}

\author{
From the Department of Cardiothoracic Surgery, Stanford University School of Medicine, Stanford, Calif. \\ Disclosures: Authors have nothing to disclose with regard to commercial support. \\ Received for publication Dec 4, 2017; accepted for publication Dec 4, 2017; available ahead of print Jan 6, 2018. \\ Address for reprints: Jack H. Boyd, MD, Department of Cardiothoracic Surgery, Stanford University School of \\ Medicine, 300 Pasteur Drive, Stanford, CA 94305 (E-mail: jackboyd@ stanford.edu). \\ J Thorac Cardiovasc Surg 2018;155:1472-3 \\ $0022-5223 / \$ 36.00$ \\ Copyright (c) 2017 by The American Association for Thoracic Surgery \\ https://doi.org/10.1016/j.jtcvs.2017.12.017
}

The use of robotic technology for mitral valve repair is wellaccepted, with outstanding short- and long-term results published by high-volume robotic mitral surgery programs. $^{1-4}$ Nevertheless, robotic mitral valve repair remains a niche practice. Although it is clear the surgical robot can be an effective tool in the hands of experts, the process of becoming an expert is daunting enough to potentially cause some surgeons to avoid robotic technology while ultimately humbling others who may be overconfident.

In this issue of the Journal, Kesävuori and colleagues ${ }^{5}$ provide an honest and detailed evaluation of the introduction of robotic mitral valve repair to their clinical practice. Comparing their first 142 patients who underwent robotic mitral valve repair with a propensity-matched cohort of historical control patients who underwent mitral repair via sternotomy, the authors found similar rates of successful repair (98.6\% vs 97.9\%), postoperative survival (99.3\% vs $100 \%)$, and repair durability at 15 to 21 months' follow-up $(86.3 \%$ vs $84.7 \%)$ between the 2 groups, respectively. Although operation length, cardiopulmonary bypass time, and crossclamp time were all significantly shorter in the sternotomy group, a significant reduction in all of the aforementioned was demonstrated in the robotic group after the first 30 patients. Importantly, more serious complications occurred in the robotic group, including left circumflex artery injury in 2 cases and low cardiac output syndrome requiring extracorporeal membrane oxygenation support in 3 cases, including 1 death. None of these serious complications occurred in the sternotomy group. Finally, nearly $10 \%$ of robotic cases were ultimately converted to open surgery, with aortic endoclamp or cardioplegia issues representing the most common cause for conversion.

This report serves as a real-world example of starting a new robotic mitral surgery program and does not attempt to hide the challenges associated with overcoming a significant learning curve. The authors clearly illustrate the often-overlooked fact that many pitfalls associated with robotic cardiac surgery (and minimally invasive cardiac

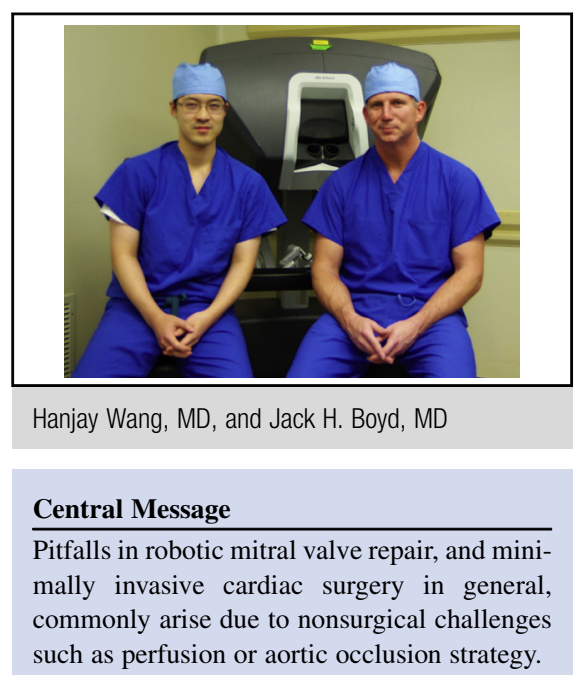

See Article page 1463.

surgery in general) lies not simply in adapting to new instruments used for surgery itself but also in familiarizing the entire surgical team (including anesthesiologists, perfusionists, and scrub nurses) to new tools used for achieving excellent myocardial protection in a closedchest environment. The authors recognized, in hindsight, that using an endoaortic balloon during robotic cardiac surgery entails its own distinct learning curve and that simultaneously adapting to both the robot and endoclamp, in combination with evolving cardioplegia strategies, may have contributed to a relatively high rate of inadequate myocardial protection and conversion to open surgery.

Although this study by Kesävuori and colleagues ${ }^{5}$ is limited in its analysis by the inability to match patients based on cardioplegia delivery and aortic occlusion strategy, the authors' overall characterization of a maturing robotic mitral surgery program is valuable as more and more cardiac surgery practices begin to adopt minimally invasive approaches. Their recommendation that new robotic mitral surgery programs use a dedicated, constant team and avoid potential overlapping learning curves represents wise advice from a nowexpert program. Therefore, may we all remain mindful of the fact that successful cardiac surgery requires not only technical skill but also effective management of other intraoperative issues, including perfusion and myocardial protection. 


\section{References}

1. Nifong LW, Rodriguez E, Chitwood WR Jr. 540 consecutive robotic mitral valve repairs including concomitant atrial fibrillation cryoablation. Ann Thorac Surg. 2012;94:38-43.

2. Murphy DA, Moss E, Binongo J, Miller JS, Macheers SK, Sarin EL, et al. The expanding role of endoscopic robotics in mitral valve surgery: 1,257 consecutive procedures. Ann Thorac Surg. 2015;100:1675-81.

3. Suri RM, Dearani JA, Mihaljevic T, Chitwood WR Jr, Murphy DA, Trento A, et al. Mitral valve repair using robotic technology: safe, effective, and durable. J Thorac Cardiovasc Surg. 2016;151: 1450-4.

4. Gillinov AM, Mihaljevic T, Javadikasgari H, Suri RM, Mick SL, Navia JL, et al Early results of robotically assisted mitral valve surgery: analysis of the first 1000 cases. J Thorac Cardiovasc Surg. 2018;155:82-91.e2.

5. Kesävuori R, Raivio P, Jokinen JJ, Sahlman A, Teittinen K, Vento A Early experience with robotic mitral valve repair with intra-aortic occlusion. J Thorac Cardiovasc Surg. 2018;155:1463-71. 